\title{
WOMEN HEALTH AND MENSTRUAL HYGIENE MANAGEMENT IN NATURAL DISASTERS: A STUDY IN ISLAMPUR UPAZILA OF JAMALPUR DISTRICT
}

\author{
SYEDA SHAHIDA MAKNUN, NAZNIN NAHAR AND MD. HUMAYUN KABIR \\ Department of Geography, University of Dhaka, Dhaka-1000, Bangladesh
}

\begin{abstract}
The study examines health and menstrual hygiene management of disaster affected women at Kulkandi Village under Islampur Upazila of Jamalpur District and explores their needs and problems regarding menstrual hygiene issues during disasters. This present study based mainly on primary field investigation including questionnaire survey with women and girls, focus group discussions (FGDs) and key informant interviews (KIIs) reveals that unhygienic sanitation and unclean water during disaster leads them to severe health issues including gynaecological problems. A significant number of respondents (21\%) experienced urinary tract infections and $24 \%$ faced rashes on sensitive private parts of their bodies. Managing their menstruation and maintaining a good standard of menstrual hygiene is difficult for them because of the factors established in this study, such as inadequate knowledge, culture and traditions, inadequate facilities and services, poverty and lack of access to health care. Effective cooperation from both the government agencies and NGOs is needed to promote good menstrual hygiene management (health care issues, sanitary pads in relief materials, workshops) in the study area.
\end{abstract}

Key words: Menstrual Hygiene, Natural disasters, Vulnerability of women and girls, Kulkandi, Jamalpur

\section{Introduction}

Bangladesh is a low lying delta with very gentle slopes and is located at the lowest end of the Ganges, Brahmaputra and Meghna Basin (Roy et al. 2009). The geographical location of Bangladesh, its low relief of the land, seasonality of monsoon precipitation, intricate networks of rivers and streams, and the funnel shape of the coastline at the head of the Bay of Bengal make it highly vulnerable to natural hazards. The problem is further aggravated by the high concentration of a very large population in a small area, exposing the region to disasters causing loss of lives and assets. The typical geographical features have significant impact on the climate system of Bangladesh that makes it one of the worst victimized countries on earth causing significant loss of lives and properties (Nizamuddin 2001). The consequences of natural disasters not only affect the overall population but also it unequally affects the rich and the poor and it is unequal in terms of 
gender. Natural disasters reinforce, perpetuate and increase gender inequality, making situations from bad to worse for women in Bangladesh. A study of 4,605 natural disasters found that disasters shortened women's life expectancy significantly more than men's (encouragingly, this association was reduced where women's status is more equal) (Rahman 2013). Many women are made vulnerable not only due to lack of access to sources of emergency information, health, hygiene and sanitation opportunities but also lack of decision-making power in disaster prevention and preparedness programs. Moreover, they are also often excluded from disaster recovery operations and from planning at the national level. This caused a reason for the intensive search for women specific health problems, risks and adaptation strategies.

Globally about $52 \%$ of the female population is of reproductive age, meaning menstruation is part of their normal life and menstrual hygiene is therefore an essential part of basic hygienic practices (House et al. 2012). Though menstruation is a natural process, it has been and still is a matter of secrecy in most of the developing countries including Bangladesh. It is a neglected issue when it comes to research or relief or recovery activities during or after disaster. Women health, hygiene especially menstrual hygiene is not given much importance in the context of Bangladesh. At the same time literature review indicates that not enough academic and research study were undertaken to analyze the impact of disasters on women's health and menstrual hygiene and their coping strategies adopted at the northern part of Bangladesh. The present study was conducted at Kulkandi Union of Islampur Upazila, Jamalpur district, one of the remotest and disaster prone areas in Bangladesh, with the aim to explore women's health and hygiene condition especially menstrual hygiene situation, preparedness, risk and loss, cultural and conditional behaviour, adaptability and recovery capacity from the natural disasters. The study was conducted to analyze the impact of disasters on women physical and mental health and menstrual hygiene condition including their needs and problems to survive throughout the disaster; to explore their own preparedness techniques and recovery strategies; to assess health care services available for women in the study area and to identify the drawback programs or activities taken by the government and other organizations for disaster affected women. 


\section{Materials and Methods}

Both qualitative (focus group discussion and key informant interview) and quantitative (household survey) techniques have been applied in this study. Households were selected through random sampling technique. Primary data were collected by triangulation of different data collection techniques of household survey, focus group discussion (FGD) and key informant interviews (KIIs). As Kulkandi is a small village with homogenous characteristics in terms of livelihood pattern, civic facilities and environmental conditions, 100 household surveys, 3 FGDs and 5 KIIs were conducted using semistructured questionnaires. Adolescent girls, middle aged women, aged women having menopause were chosen as respondents for household survey. On the other hand, FGD groups consisted of female participants of three groups such as adolescent school going girls, adolescent girls who are not going to school and middle aged women. Both informal contact and cold-calling approaches were utilized to reach participants for FGD. KII was done with the local CDMC women president, Bangladesh Red Crescent Society's girl volunteer, FWC (Family Welfare Centre), female doctor, Jamalpur Sadar Hospital gynaecologist and nurse of the hospital. The surveyed data were then processed and analyzed using Statistical Package for Social Science (SPSS) IBM 20 and Microsoft Office Excel software.

Study Site: Kulkandi Village (Fig. 1) under Kulkandi Union is located in Islampur Upazila of Jamalpur District, the northern part of Bangladesh which is badly affected by floods every year and therefore, it has been purposively selected for the present study area. It has an area of 7,024 acres and 400 households (Hasan 2014). This is one of the most vulnerable villages in the union as every year the inhabitants of this village suffer due to severe monsoon floods. Kulkandi is frequently affected by flash floods and water logging for its geographical location as it is surrounded by the Garo hills to the north and the major hydrological regime of the district is influenced by the Jamuna River and its distributaries. The Jamuna brings in huge quantum of water during monsoon inundating vast low-lying areas along the Jamuna flood plains. Flood generally occurs along the Jamuna system, while flash flood generally occurs along the smaller rivulets adjacent to the Garo Hills. Flash floods are short lived phenomenon, while only a few hours of intense rainfall can effectively make the area inaccessible for over a day or two. However, the quickly on-setting nature of the hazard washes away almost everything on the way of rushing runoff. Not only standing crops are devastated, physical infrastructure (especially roads and poorly constructed culverts, hospitals) are often devastated. This condition creates vulnerable condition for the women health in this region as they extremely lack of knowledge on menstrual hygiene and sanitation. 


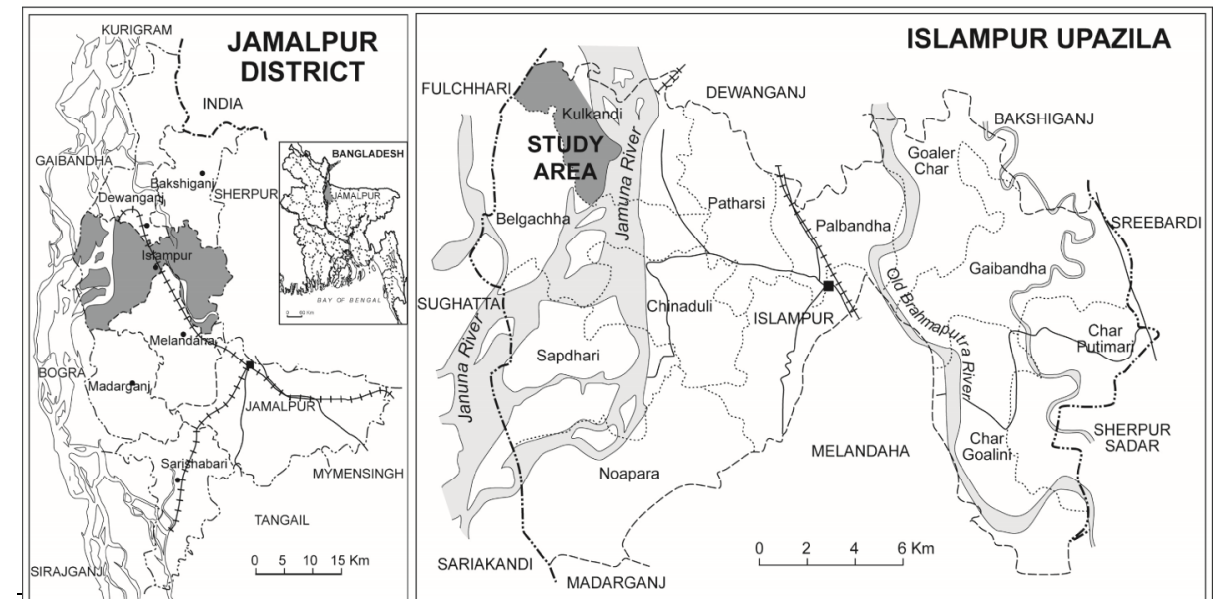

Fig. 1. Location of the study area.

\section{Results and Discussion}

Demographic and Socio-Economic Background: Age, marital status, religion, education, occupation and income are important socio-economic factors in menstrual hygiene management situation analysis. In order to know the situation of women and girls in the study area, age group selection was very important. Adolescent girls group aged from 11 to 20 years ( $24 \%$ of the respondents), youth group aged from 21 to 30 years (34\% of the respondents), middle aged women group aged from 31 to 40 years (23\% of the respondents) and elder women having their menopause aged from 41 to 50 years (19\% of the respondents) were selected for the household survey.

Menstruation is referred as the girl is ready to be married when she has her first menstruation. In the study area, percentage of married respondents is high $(73 \%)$, whereas only $19 \%$ of them are unmarried. Around $2 \%$ women were separated while $6 \%$ of these women are widows. Even adolescent girls were married at the age of 12 or 13 after their first menstruation. Being married at such an early age is not an uncommon scene in the rural areas of Bangladesh.

Religious status is another important determinant to know the menstrual practices in the study area as menstrual taboos and management varies from religion to religion. In the study area mainly two types of religion (Islam and Hinduism) are dominant. Among the respondents $88 \%$ are Muslims and other $12 \%$ are Hindu respondents.

Educational background is important as educated women and girls are aware of proper menstruation hygiene practice. More than half $(56 \%)$ of the respondents are literate, while $46 \%$ of women have completed primary education but then they left school 
because of poverty and getting married and $10 \%$ have completed high school education, while about $44 \%$ of the respondents are illiterate.

Employment status was measured in terms of the respondents own and the head of the household in the study area. Among the 100 respondents, majority of the respondents $(65 \%)$ are housewives including the adolescent married girls, young girls, middle aged women and older women. Around $20 \%$ of the respondents were students and only $17 \%$ women are housemaid. Household head occupations of the respondents were found diversified including farmers (34\%), day labourers (28\%), fisherman (14\%), small business $(12 \%)$, service holders including govt. and NGO workers $(9 \%)$ and auto driver (3\%) in the study area. Economic condition of the people at Kulkandi is not well-off which is evident from their housing structure. More than $80 \%$ of the houses are katcha (floor, wall and roof of these houses are made of earth material, bamboo, thatch or wood). Besides, only $2 \%$ houses are brick-built, which can be considered as disaster resilient. Semi pucca houses are resilient to storm and flood. Overall, all of the houses, except very few, are physically highly vulnerable to any disasters.

\section{Occurrence and Impacts of Disasters in the Study Area}

Major Disasters: As mentioned earlier, the study area is subject to frequent floods. Although the district as a whole is prone to seasonal drought and riverbank erosion, the study area vulnerable to flash flood, river flood and water-logging. River flood (38.5\%) associated with flash flood $(28.3 \%)$ are the major disasters in the study area. Waterlogging $(24.8 \%)$ is the during-disaster and after-disaster effect of the floods. Riverbank erosion $(8.4 \%)$ is also perceived as one of the threats increasing gradually in the study area.

Early Warning System and Shelters during Disasters: From the study, it has been found that $72 \%$ get early warning of disasters. From the FGDs it is found that they receive early warning from the masjid Imam or Red Crescent volunteers in the locality whereas other $28 \%$ don't receive early warning but they can identify the disaster time by observing the flow and color of the river water and full moon.

In the study area, $46.8 \%$ of the respondents mentioned that they take shelter on the dam during floods, whereas $23.7 \%$ take shelters in madrasa as their houses go under water. About $20 \%$ of the respondents stay at home using macha and they try to survive somehow. Respondents having strong brick-built house normally remain safe during floods. Another $10.9 \%$ said that they stay with their relatives.

Impacts of Disasters: Impact of disasters includes the socioeconomic problems created due to disasters, availability of the relief after the disasters and diseases that occur during and after the events causing huge problems and sufferings in the lives of the people. Their normal lifestyle becomes badly affected and they suffer from unemployment leading them to poverty. Health and sanitation practices are extremely unhygienic during and post disaster periods, which creates the outbreak of various diseases. Female are more vulnerable and neglected during disaster in the context of health, hygiene and sanitation 
in the study area. Table 1 shows the problems created due to the impacts of disasters in the study area.

Table 1. Problems created in the study area due to disasters.

\begin{tabular}{lcc}
\hline \multicolumn{1}{c}{ Problems } & $\begin{array}{c}\text { Number of responses } \\
\text { (Multiple Responses, N) }\end{array}$ & Percentage \\
\hline Food shortage & 84 & 14.61 \\
Scarcity of drinking water & 91 & 15.83 \\
Outbreaks of different types of & 75 & 13.04 \\
diseases & & \\
Scarcity of fodder & 39 & 6.78 \\
Increasing food price and other & 77 & 13.39 \\
commodities & & \\
Sanitation problems & 86 & 14.95 \\
Damage of houses & 19 & 3.30 \\
Poverty & 73 & 12.69 \\
Unemployment & 26 & 4.52 \\
Don't know & 5 & 0.87 \\
\hline Total & $\mathrm{N}=575$ & $100 \%$ \\
\hline
\end{tabular}

Relief Facilities: Among all the respondents, around half of the respondents who received relief in the past disaster claimed that sufficient relief was not supplied. Food such as chal, cheera and gur are given as food materials to the flood affected people. The family welfare centre in Islampur had given free medicine to the flood affected people. This free medicine included only food saline and normal painkillers.

Outbreak of Diseases due to Disasters: Unhealthy and unhygienic conditions are prevalent in the study area during and post disaster periods. During disaster, a majority of the respondents cannot afford to take boiled water and as a result diarrhoea, typhoid and dysentery are very common during this time. Skin diseases are also severe in this period as people have to live with unhygienic condition and continuous contact with contaminated water (Fig. 2).

Female are mostly affected due to these diseases severely as they feel neglected at the time of disaster. Moreover, they have to look after the family members. Skin diseases are common among the women and girls of all ages.

Water and Sanitation Condition: Unclean water and lack of access to hygiene and sanitation during disasters are sources of health hazards for women. Water is essential life element which is frequently used by women to care for children, the elderly and the sick, as well as to carry out many household tasks (Rahman 2013). During disasters, sanitation becomes a problem as women and girls carry the highest risk of getting in contact with polluted water and falling sick during and after disasters (Mehta 2007 and Dasgupta et al. 2010). Water-borne diseases might be expected to be more widespread among women, who are nutritionally disadvantaged (Rahman 2013). 
a Percentage of Responderts

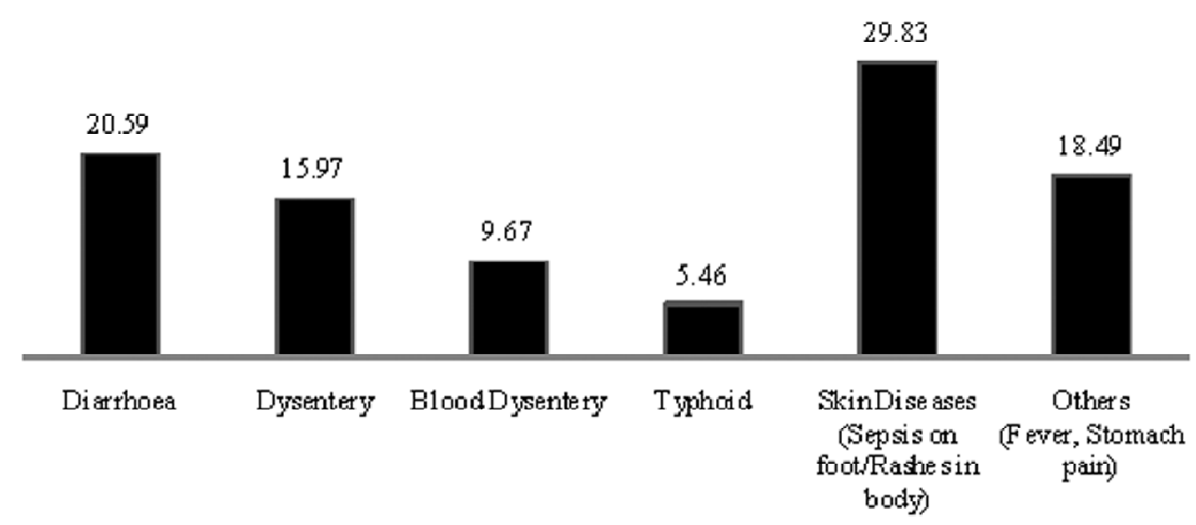

Fig 2. Outbreaks of diseases during and post disaster periods.

Drinking Water Sources during Disaster Period: Nearly half of the respondents collect water from the Jamuna River during normal period. Another around $40 \%$ of the respondents use deep tube-well water and other $17 \%$ of the respondents collect water from ponds in the study area. The situation gets changed during flooding events. Around one fourth of the respondents collect water from deep tube-well during disasters whereas a majority of the respondents $(60.8 \%)$ collect water from river water as they have to live on the embankment. Therefore it is easy to collect the river water or flood water in that time. Only $13 \%$ of the respondents collect water from ponds which are not affected by flood water but these are located far away. It is beyond doubt that during disasters a majority of the respondents collects drinking water from river which is highly unhygienic. Drinking water sources can be a good indicator that helps to understand the reason behind the occurrences of different diseases in the study area. As water borne diseases become severe during disaster, women and children become mostly affected by this and also women have to be in contact with the unclean water for a long time to maintain their family member's need. Various kinds of skin diseases are also common in disaster period due to the continuous contact with the unclean water.

Purifying Techniques: Drinking unclean water without purification is the main cause of diarrhoea, dysentery and typhoid types of water borne diseases. During disaster $72 \%$ of the respondents drink water without boiling whereas only $28 \%$ uses purification techniques (e.g., tablets or fitkiri or drink tube-well water directly which are not affected by flood water). 
Sanitation Facilities: During disasters, $70 \%$ of the respondents mentioned about their own modifying toilet facilities which is called "kala gacher vela" made of banana tree, mainly a floating toilet women and girls use for sanitation. This technique is undoubtedly very unhygienic and risky for women as there are no sanitation facilities, safety and security in this type of toilet. Fifteen percent of the respondents use sanitary latrines of school or latrines that are not inundated during flood time. They have reported that they can't use the toilets of madrasas because they are not allowed to go to the toilets which create sanitation problems. Other $15 \%$ of the women have said that they go to open place during nights in the flood time as there are scarcity of sanitation facilities for 400 families during floods. They face shyness and security problems so they use the toilets in nights and control their needs for going to toilets during day by not drinking enough food and water. Besides going to use toilets that are far way costs them to wet themselves on their way to toilets and shelter which makes them more careless about toilet facilities during disaster.

\section{Women Health and Menstrual Hygiene Management in Disasters}

Generally women spend around six to seven years of their lives menstruating so menstrual hygiene is a vital and very sensitive issue for women in reproductive ages. Every woman has the right of having safe, personal and cultural surroundings to manage their menstruation in healthy and hygienic ways as well as with dignity. However, the ability to enjoy this right is often far from reality because women health is often not only a neglected issue or less important issue but also menstrual hygiene management is often neglected in general health agendas. This can be seen in emergency situations like disaster periods such as in the time of flood, cyclones etc. most temporary or permanent shelters are not women friendly and therefore women's security, privacy and health needs are largely ignored. Especially in developing countries like Bangladesh, menstruation is often handled in secrecy. In emergency situations, the normal life style of victims has changed and they are under immense psychological pressure which aggravates problems. Providing basic needs such as food and medicine gets priority while the pressing need of securing menstrual hygiene is often neglected.

Knowledge on Menstruation: Menstrual hygiene knowledge and practices of an area or community are very important to assess the overall hygiene and health management of women of that area or community. Among 100 respondents, most of the girls and women (about 49\%) have experienced their first "period" at the age from 10 to 12 years, while $46 \%$ of them have their first period in 13-15 years age and very few (only 5\%) women and girls have their period in years between 16 to 18 years. 
A girl's first menstruation is called menarche. Most of the respondents (72\%) of the study area don't have the knowledge of menstruation before menarche. It has been explored from the study that most of the women and girls do not have adequate knowledge on menstrual hygiene management and they have got their first knowledge on menstruation after having their first "period"/menstruation. Recently some of the respondent (28\%) especially adolescent girls (especially those are in secondary high schools) are getting this knowledge from school and friends but their percentage is low. From the FGD of adolescent school going girls, it is found that Menstruation education is not taught at primary level at all, and at secondary level only in biology and home economics, which are not compulsory for everyone. Just over $50 \%$ of girls and women got their first knowledge of menstruation from their sister and sister in law as they feel hesitation to talk about it with their mother whereas $31 \%$ of them get knowledge from friends and $15 \%$ get knowledge from their relatives.

Regularity of "period" is a good sign of menstrual hygiene maintenance. Irregular period is not a symptom of good hygiene. A majority (58\%) of the women are having regular period which also include the girls $(7 \%)$ having experience of the menstruation recently (less than 5 months). Around 30\% are having irregular period and a little portion of them are taking medicine from Family Welfare Centre (Ma Ebong Shishu Kalyan Kendra) to continue their period. From the key respondents (Family Welfare Centre Doctor), it has been found that they have patients regarding irregular period who have come to them for medicine to regulate their menstruation. $14 \%$ of the women have experienced their menopause in the study area.

Menstrual practices: During menstruation, it is common for the Bangladeshi woman, especially from poor socio-economic background to use pieces of old clothing to absorb blood. A significant number $(56 \%)$ of the women uses old cloths or rags in their menstruation time. Only a few girls $(11 \%)$ use sanitary pads. Some of them (14\%) use both sanitary pads and rags for menstruation. Just over $15 \%$ of the women especially elderly women use nothing as they said that they experience lower blood flow which is extremely unhygienic. Only $2 \%$ of female respondents use cotton as sanitary pads is too costly for them.

Menstrual hygiene can be maintained through changing the cloths/rags or pads of every 4 hours which is necessary for maintaining gynaecological health. But it is not possible for rural women and girls to change their cloths in that interval as they are not aware of proper menstrual hygiene maintenance. Over 50\% women (13\% adolescent and $41 \%$ women) change their menstrual cloths once per day whereas $37 \%$ (9\% adolescent and $28 \%$ women) of the respondents change the menstruation cloths/pads twice per day. Only 
9\% (2\% adolescent and 7\% women including youth and middle aged group) of the respondents change their cloths three times per day.

Cleaning and Drying Techniques of Menstrual Cloths: Management of used cloths include washing and reusing of the cloths and also the disposal of cloths. Around $90 \%$ of the respondents wash and reuse their cloths. Some (11\%) dispose their cloths after it is too old to use or they dispose their sanitary pad after one use and mainly bury them in soil. In the study area around three fourth of the respondents use soap and water in normal time while washing their menstrual rags. Only $26 \%$ uses only water to clean which is extremely unhygienic. They mainly clean their cloths after the menstruation is over completely.

According to female respondents, drying of cloths is a matter of shame to them. They want to dry their menstruation cloth very secretly so that the male members in the house can't see it. More than $26.9 \%$ of the respondents dry their cloths on the roof of their house with other cloths. But most of them $(31.4 \%)$ dry their cloths in the corner of their room with other cloths and in the monsoon time they use the dump cloths again though it is no completely dry. Just over $20 \%$ of the respondents dry their cloths beside the side of the toilet walls whereas only $18.59 \%$ of the respondents dry their menstruation cloths in sunlight but covered with other cloths.

Menstrual Hygiene Management Scenario during Disasters: The menstrual hygiene management during normal time is different than the time of disaster as the situation is not friendly and cooperative enough during disaster. Only $18 \%$ women and girls store their menstrual cloths (clean cloths and sanitary pads) if they have the probability of having menstruation in that time. Majority of the respondents $(82 \%)$ have no preparation regarding menstruation hygiene before disaster. There is a difference in the time of disaster and in normal time in regards to using menstrual cloths. It is not possible always to buy the sanitary pads before the disaster so majority such as $62 \%$ of the respondents use menstruation rags during flood time. Only $6 \%$ of the respondents use sanitary pads and other $9 \%$ use the both. $23 \%$ of the respondents use nothing as they have nothing to use and it is difficult for them to clean the cloths during the flood time. As it is difficult to clean and reuse the cloths during disaster period, the disposal rates of menstruation cloths increases in this time. $19 \%$ of respondents especially the adolescent girls dispose their cloths or rags after menstruation as they feel lazy to clean it. But $81 \%$ of the respondents clean it in the flood water and reuse it which is very unhygienic.

Among them about $56 \%$ of the respondents only use soap and water for cleaning their menstrual cloths during disaster but they clean their cloths not only with the cleaning soap but also with the soap they use to clean body which is not hygienic whereas $44 \%$ of 
the respondents use only flood water to clean their cloths as it is difficult to manage soap all the time. Middle aged and older women are careless about cleaning their cloths. At Kulkandi, the respondents mentioned that it becomes more difficult to dry their cloths during the time of floods as they have to take their shelter in riverbank dam. They have to clean and dry their menstruation cloths in home coming from shelter by walking in the flood water and they become wet as it is shameful for them to clean or dry the cloths before male members. $62 \%$ of the women dry their cloths on the roof of the houses during this time as the roof are not inundated this time. Those who live in house or shelters dry their cloths with other cloths in the corner of the shelter or house. Other $12 \%$ of them dry their cloths in sunlight with other cloths.

Health Problems of Women and Girls: The respondents in the study area face many health problems regarding their menstruation. More than $32 \%$ of the female respondents have abdominal pain with weakness during menstruation. $24.48 \%$ of the respondents have rashes in their private parts during flood time or normal time as they don't clean the cloths or maintain any hygiene practices during or before disaster. $21.99 \%$ of the respondents have reported about having urinary tract infection and this is because they eat less and don't drink enough water and using one cloth for too long time during menstruation. $19.09 \%$ of the respondents reported about vaginal infection which increases after the flood according to them. A very tiny fraction of the respondents $(0.02 \%)$ of the respondents are having ovary cyst and irregular period because of that.

Social Problems: Health problems are also associated with social problems in the study area. Women and girls in the study area face many social problems during disaster. Physical assaults become common while living in the shelter or riverbank as there is no privacy or safety situation. Adolescent girls and young women become mostly victimized by physical assault by the young boys. Family members try to save their girls from the evil boys and men. Women have reported about domestic violence from their husband and male children. During the time of disaster the earning person of the family became unemployed that creates frustration so they become angry and often beat their wives and girl children without any reason. $15 \%$ of the women have reported about sexual harassment such as being inappropriately touched by other men while staying in embankments when they go to collect water or washrooms. Privacy becomes a severe problem during the disaster period. Fig. 3 shows the social problems faced by the women during disasters in the study area. 


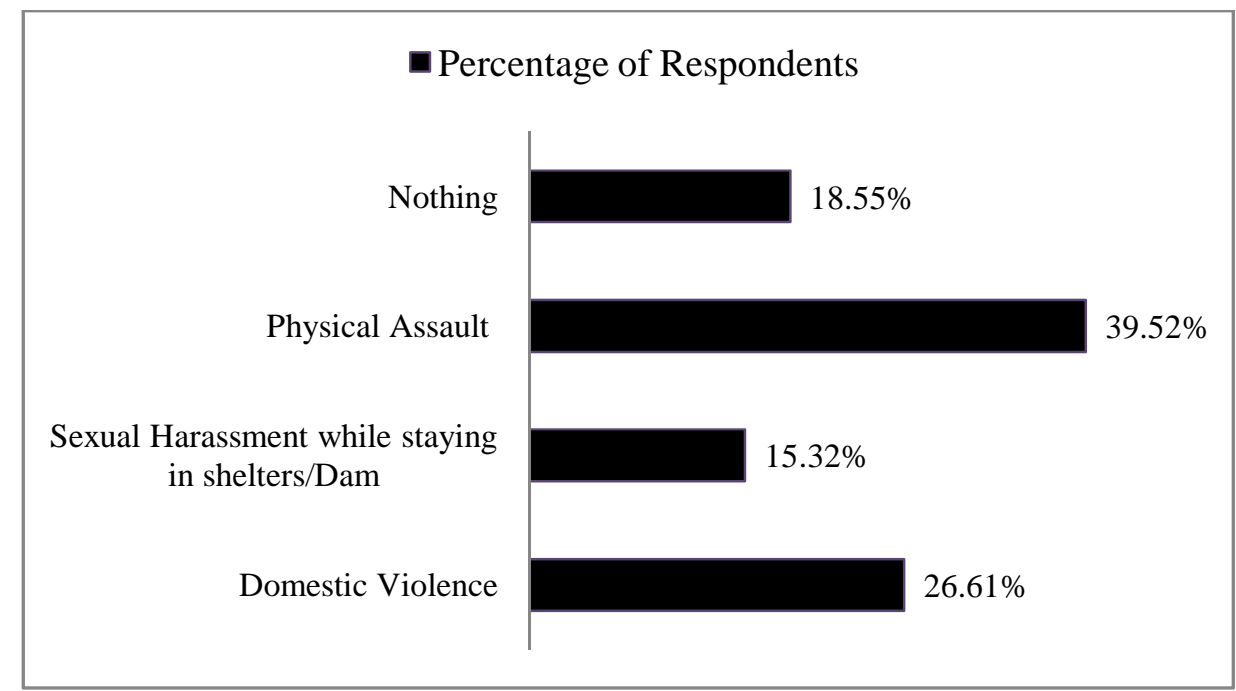

Fig. 3. Social problems faced by the respondents during disasters.

Availability of Menstrual Health Care Facilities: All of the respondents have reported that they have no health care facilities regarding menstrual hygiene in the study area Kulkandi. They have to go to upazila hospitals or Jamalpur Sadar hospital or family welfare clinics for getting help for gynaecological problems. For their gynaecological problems women feel shy to go for hospitals or clinics. Among all the respondents, $47 \%$ of the respondents go to MBBS doctors in the upazila hospitals or other private hospitals for their gynaecolocial health problems in the study area. Twenty eight percent still go to kabiraz or jharfuk for their health related problems like menstruation problems, pregnancy, typhoid, jaundice etc. and $25 \%$ of the respondents go to local quacks as they are too poor to see a MBBS doctor.

Availability of Normal Health Care Facilities: According to most of the respondents $(22.96 \%)$, Sadar hospitals have all the facilities so they go there for their treatment. Other female respondents about $19.07 \%$ go to Dewanganj and $20.62 \%$ of the respondents go to Islampur Upazila Hospital as these two are not more distant from Kulkandi. As Kulkandi clinic has very few facilities, only $17.90 \%$ of the respondents go there for their normal problems like fever or diarrhoea treatment. Only $5.05 \%$ of the respondents are able to go to private clinics because these clinics are costly (Table 2). 
Table 2. Respondents visiting different health care centres.

\begin{tabular}{lcc}
\hline Types of health care centres & $\begin{array}{c}\text { Frequency (Multiple } \\
\text { responses, N) }\end{array}$ & $\begin{array}{c}\text { \% respondents visit these } \\
\text { places }\end{array}$ \\
\hline Kulkandi Health Clinic & 46 & 17.90 \\
Islampur Upazila Hospital & 53 & 20.62 \\
Dewanganj Upazila Hospital & 49 & 19.07 \\
Jamalpur Sadar Hospital & 59 & 22.96 \\
Family Welfare Centres & 37 & 14.40 \\
Other Private Clinics & 13 & 5.05 \\
\hline Total & $\mathrm{N}=257$ & $100 \%$ \\
\hline
\end{tabular}

During the time of disaster only $44 \%$ get their health care facilities from the health clinic of BDRCS in Kulkandi Union. The male doctor visits the study area every three months. But women is deprived of that regarding menstruation as the clinic has only one male doctor so they feel hesitation and cannot tell their problems regarding menstruation. Only $25 \%$ of the female respondents get the health care facilities such as saline and painkillers for fever during disaster from Family Welfare Centre but nothing for their gynaecological problems. Other $31 \%$ of the respondents don't get any facilities during disaster.

Existence of Awareness or Training Programs: Awareness on MHM (Menstrual Hygiene Management) is very poor in the study area. Though Bangladesh Red Crescent Society (BDRCS) has organized trainings on MHM in 2015, still they are not aware enough to maintain proper hygiene during their menstruation. Only the adolescent girls are aware and try to maintain their menstruation practices hygienic. Adolescent girls also have the menstruation education in school in class eight but the education is not compulsory for every student. Only $23 \%$ of the respondents are aware of MHM where most of the respondents $(77 \%)$ are not aware of any training or awareness program of MHM.

Work Management of the respondents during disaster: It is found that during the disaster, $36.28 \%$ of the respondents were busy with their family maintenance and management. $30.23 \%$ of the female respondents did the cooking for their family members and $20 \%$ were responsible for collecting drinking water from shelter or tube wells and $13.49 \%$ of the respondents are responsible for collecting relief facilities as men become too lazy and frustrated during this time.

Types of Decision Made by Women before and after Disasters: Decision making power before the time of disaster and after disaster is the indicator of women's position and empowerment in a society. Women are mainly responsible for family management and even their house management. Tables 3 and 4 show the types of activities including decision making by the women during and after disasters. 
Table 3. Types of decision taken by women before disasters.

\begin{tabular}{|c|c|c|}
\hline Types of decision & $\begin{array}{l}\text { Frequency (Multiple } \\
\text { responses, N) }\end{array}$ & Percentage \\
\hline Storing Menstrual Cloths/pads & 18 & 7.32 \\
\hline Storing dry foods & 44 & 17.89 \\
\hline Storing fuels & 38 & 15.45 \\
\hline Be aware and create awareness & 19 & 7.72 \\
\hline Store necessary things & 52 & 21.14 \\
\hline Savings & 46 & 18.70 \\
\hline $\begin{array}{l}\text { Creating sanitation facilities for } \\
\text { women }\end{array}$ & 29 & 11.79 \\
\hline Total & $N=246$ & $100 \%$ \\
\hline
\end{tabular}

Table 4. Types of decision taken by women after disasters.

\begin{tabular}{lcc}
\hline Types of Decision & $\begin{array}{c}\text { Frequency (Multiple } \\
\text { Responses, N) }\end{array}$ & Percentage \\
\hline Reconstruction or cleaning houses & 79 & 32.24 \\
Cleaning debris & 84 & 34.28 \\
Helps in earning & 18 & 7.36 \\
Help others & 64 & 26.12 \\
\hline Total & $\mathrm{N}=245$ & $100 \%$ \\
\hline
\end{tabular}

Findings related to Menstrual Hygiene Management of Adolescent Girls and Women: Menstrual Hygiene management problems are age specific. From the Qualitative research method (FGD and KII survey), it has been identified that the needs and problems of adolescent girls and women are different. Findings from the study reveal that adolescent girls miss their school 2 to 3 days every month. Many girls do not learn about menstruation until they menstruate themselves and, when they do, they have many unanswered question. It is also reported that menstruation is a topic that should be kept secret and it cannot be discussed openly. Most of the girls do not prepare for their period to arrive and go home from school when it happens and they become less active and participate less in daily life when menstruating. They receive most of their information and practices regarding menstruation from sister, friends, sister-in laws and mother. They desire to have access to disposable pads but they have no dispose dustbin in the school for sanitary pads that makes them uncomfortable to dispose and they carry it to home and then dispose it by burying them in soil. Some schools have separated washrooms for girls and boys but not with hygiene facilities like soap for hand wash. Finally, the price of the sanitary pads is very costly. In Kulkandi Village, the price of the sanitary pads were found very high (such as 120 Taka) for each sanitary pad packet whereas in Sadar the price is only 70-80 Taka per packet. 
Findings from adolescent girls who are not going to school: They mainly use rags but don't change them much (once a day) when menstruating. They do not eat much this time. During flood they have only a little meal in this time. They believe that it will decrease their blood flow which is good. They feel uncomfortable in using cloths as they have to clean it for a long time and bloods is not fully soaked in the rags. During disaster they don't have the facilities to clean their menstruation rags properly and they don't have the place to dry. As a result they often use the dump, unclean rags. They feel abdominal pain and weakness during menstruation and they do not have the energy to do the housework during their menstruation time. They have to go to washroom less during flood time so they eat and drink less food and water. They do not go out much during this time.

Findings from middle aged women: Women are careless about the changing of their rags. They mainly change their rags once in a day. They are careless about hygiene too. They often don't use any cloths during disaster and don't use soap to clean the rags during floods. They clean their rags with unclean flood water and they don't get any health care facilities regarding menstruation hygiene. They don't get any relief facilities for menstruation practices like cloths or pads. They have no female doctor in the health care clinic in Kulkandi. Very often they use dump cloths when they don't find enough chance to dry their cloths

Myths and Taboos: From FGD, It was found that myths and taboos were not that much strict in the area but still those exists such as for Muslim women praying and touching religious books or going to Masjid is strictly prohibited whereas for non- Muslims such as for Hindu women participating in pujas are prohibited. There are others taboos such as:

- "Eat less amount of food so that blood flow will be low".

- "Don't drink water too many times so that there will be no need to go to washroom several times".

- "Don't go outside after sunset, otherwise there will be evil influence (kharap batash) on you!"

- "Don't eat fish and meat (No fishy smell from blood)"

The present study reveals that women are unfairly treated when they extremely require satisfying their needs particularly in terms of menstrual hygiene before and during disaster. Though menstruation is a natural process, it has been and still is a matter of secrecy in most of the developing countries including Bangladesh. Women and girls are more vulnerable than men and during disasters there is no special relief facility regarding health and menstrual hygiene for them in the study area. Unhygienic sanitation and unclean water during disaster leads them to severe health issues including gynaecological 
problems. The study identified that menstruating girls and women face tremendous challenges during disasters. Managing their menstruation and maintaining a good standard of menstrual hygiene is difficult for the women and girls because of the factors existing in the study area, such as inadequate knowledge, culture and traditions, inadequate facilities and services, poverty and lack of access to health care services. In order to satisfy the needs uncovered by the present study, it is needed to establish a health care clinic specialized for women and provide female gynaecologist and nurses as early as possible. Govt organizations and NGOs should be co-operative in terms of giving reliefs to the flood affected areas considering the menstrual hygiene management. Clean cloths and sanitary pads with free supply of medicine for skin diseases should be added in the relief materials for women. Flood shelters should be established in Kulkandi with the facility of soaps and water to promote safe sanitation including separated toilets for Male and Female population to ensure their privacy and safety during disasters. Effective cooperation between local NGOs and Government is needed to promote increased amount of food and medicine relief materials to all flood affected people specially women and children in order to maintain women and children nutrition and health care facilities. Govt. should arrange workshops and trainings on menstrual health and hygiene knowledge and management in order to create awareness among women and adolescent girls. This topic should be added as educational curriculum and made compulsory for both male and female students in order to create awareness and understanding situation. More volunteers should be trained by Govt. And local NGOs to facilitate the women and children during disaster (flood time) in community level. Menstrual hygiene management (MHM) should be included in the national level policy.

\section{Acknowledgement}

The authors acknowledge the contributions of the study participants, especially women and special thanks to Bangladesh Red Crescent Society (BDRCS) for the financial assistance to carry out the study.

\section{References}

Dasgupta, S., S. Ismail and D.P. Sarathi, (ed.). 2010. Women's encounter with disaster, Frontpage Publications Ltd, India. pp. 93-104.

Hasan, K.M. 2014. Flood assessment report on Kulkandi Community under CBDRR program, DRM Department, BDRCS. pp. 3-4.

House, S., T. Mahon, and S. Cavill. 2012. Menstrual Hygiene Matters: A Resource for Improving Menstrual Hygiene around the World. pp. 8 [Online Available: www.wateraid.org/mhm. 
Mehta, M. 2007. Gender matters: Lessons for disaster risk reduction in South Asia, ICIMOD, Kathmandu, Nepal. pp. 5-7. Retrieved from: www.gdnonline.org/resource/Gender\& disasterpreparednessICIMOD.pdf.

Nizamuddin, K. (ed.). 2001. Disaster in Bangladesh: Selected Readings, Disaster Research Training and Management Centre (DRTMC), Department of Geography and Environment, University of Dhaka. pp. 1-8.

Rahman, M. 2013. Climate change, disaster and gender vulnerability: A study on two divisions of Bangladesh. American Journal of Human Ecology, 2(2):72-82.

Roy, K. K., H. Mehedi, T. Sultana and D.M. Ershad, 2009. Initial Damage Assessment Report of Cyclone Aila with Focus on Khulna District, Unnayan Onneshan, Humanity Watch, Nijera Kori, Bangladesh. pp. 30-31.

(Revised copy received on 28/6/2017) 